\title{
MODELLING AND MEASURING WAVES IN COASTAL WATERS
}

\author{
Judith Wolf ${ }^{1}$, Pedro Osuna ${ }^{1}$, John Howarth ${ }^{1}$ and Alejandro Souza ${ }^{1}$
}

\begin{abstract}
We investigate some aspects of wave-current interaction in the modelling and observations of waves and currents in the Irish Sea. The interaction of waves and currents through the surface and bottom stress, as well as refraction of waves by currents, is included in a coupled wave-current model. Long-term measurements of currents and waves, starting in November 2002, are being made in the Liverpool Bay Coastal Observatory in the Irish Sea. The large tidal range, relatively shallow depth and waves up to $5 \mathrm{~m}$ suggest significant wave-current interactions will occur here and the measurements should provide a good test of coupled hydrodynamic-wave models. Some of the problems of getting observational data to validate or challenge these models are discussed.
\end{abstract}

\section{INTRODUCTION}

Coastal development continues to put pressure on wetland habitats, beaches and coastal defences. Concerns about the impacts of climate change exacerbate the problem for coastal managers. In order to properly manage the near-shore coastal zone, we need appropriate models of the physical, biogeochemical and ecological systems. Key challenges in coastal oceanography are the implementation of appropriate local area models and critically testing these with observations. The interactions between waves, currents and turbulence and their impacts on sediment transport become more important, with implications for ecological modelling in terms of water quality and turbidity. We investigate the need for local wind modelling, wave-current interaction, vertical and horizontal current shear, improved representation of bottom friction and turbulence modelling. Various developments in spectral wave modelling have produced a range of possible source terms especially for the wind input and dissipation source terms. Different approximations to the exact nonlinear interaction source term are also available. Our interest is in the practical implementation of the WAM model in shallow water, using the optimal source terms for this environment. In order to test the different options we need adequate observations of waves, currents and reliable wind forcing for the model.

Here we review the mechanisms of interaction which are being incorporated in the POLCOMS-WAM coupled model system and some of the key problems in making observations to test these models. We describe some of this work in progress and recent results. Specifically we look at the surface and bottom stress in coupled models and how to observe and validate these and the implications of the assumption of steady flow in wave models. New data from the POL (Proudman Oceanographic Laboratory) Coastal Observatory are presented.

\footnotetext{
${ }^{1}$ Proudman Oceanographic Laboratory, 6, Brownlow St, Liverpool, L3 5DA, U.K.
} 


\section{ADVANCES IN COUPLED WAVE AND CIRCULATION MODELS}

Recently, progress has been made towards coupling atmosphere and wave models (e.g. Janssen 2004) and in developing a consistent treatment of the equations of motion for waves, currents and turbulence (e.g. Mellor 2003, 2005). We know waves are the mechanism for transfer of energy between the atmosphere and ocean and a wave model is an important component of the system. We are interested in testing the implementation of these ideas in preoperational models such as the POL Coastal Ocean Modelling System (POLCOMS) in which a baroclinic 3D current model is coupled with the $3-\mathrm{G}$ WAM spectral wave model. These are two very different types of model: the former describes explicitly the evolution of sea surface elevation and currents due to tides, density and wind forcing (although with parameterisation of subgrid processes such as turbulence). The wave model is a phase-averaged model which describes the evolution of the wave spectrum; no information is available on phase of the individual wave components. Procedures to include the two-way interaction between currents and waves in surface and bottom stress and the refraction by changing water depth and currents have been included in the POLCOMS-WAM system (Wolf 2004, Osuna and Wolf 2005). The effect of relative wind is also included.

Some of the problems in modelling the seasonal thermocline (Holt and James 2001) are related to the turbulence and mixing model which may be affected by waves in certain situations (e.g. Langmuir circulation and Stokes' drift) and some alternative formulations have been explored (e.g. Carniel et al. 2004). For the implementation of new terms in the WCI (wave-current interaction) module of POLCOMS, the approaches described in Mellor (2003, 2005), Mellor and Donelan (2006), and Ardhuin and Jenkins (2006) are used. At present, the wave model has been prepared to calculate the following information: Stokes' drift, radiation stress and Doppler velocity for each component of the wave spectrum, to properly account for the vertical variation of current velocity. The Stokes' drift results on the Ekman circulation obtained from the WCI system were qualitatively and quantitatively similar to those reported in Rascle et al. (2006). Results with the enhanced model will be available shortly.

\section{LIVERPOOL BAY COASTAL OBSERVATORY}

Long-term measurements of currents and waves, starting in November 2002, are being made in the Liverpool Bay Coastal Observatory in the Irish Sea (see Fig. 1). Directional waves are being measured by wave buoys, ADCPs (acoustic Doppler current profiler) and ADVs (acoustic Doppler velocimeter) within the footprint of a phased-array HF radar system. Simultaneous measurements of currents, waves, bed stress and water level are made (Howarth et al. 2006). In conjunction with this, detailed process studies are being carried out in the mouth of the Dee Estuary measuring wind-stress, currents, waves and turbulence. Liverpool Bay is relatively shallow, with a maximum depth less than 
$40 \mathrm{~m}$, with tidal currents up to $1 \mathrm{~m} / \mathrm{s}$ and at the mouth of the Dee, near Hilbre Island, there are extensive sandbanks which are exposed at low water. The Irish Sea is semi-enclosed so waves are mostly locally generated, with significant wave heights up to $5 \mathrm{~m}$ recorded and mean periods less than 8 seconds. Significant wave-current interactions may occur here and the measurements provide a good test of coupled hydrodynamic-wave models. ADCP and HF radar measure waves using their surface properties and hence are not affected by depth-attenuation like the bottom-mounted ADV.

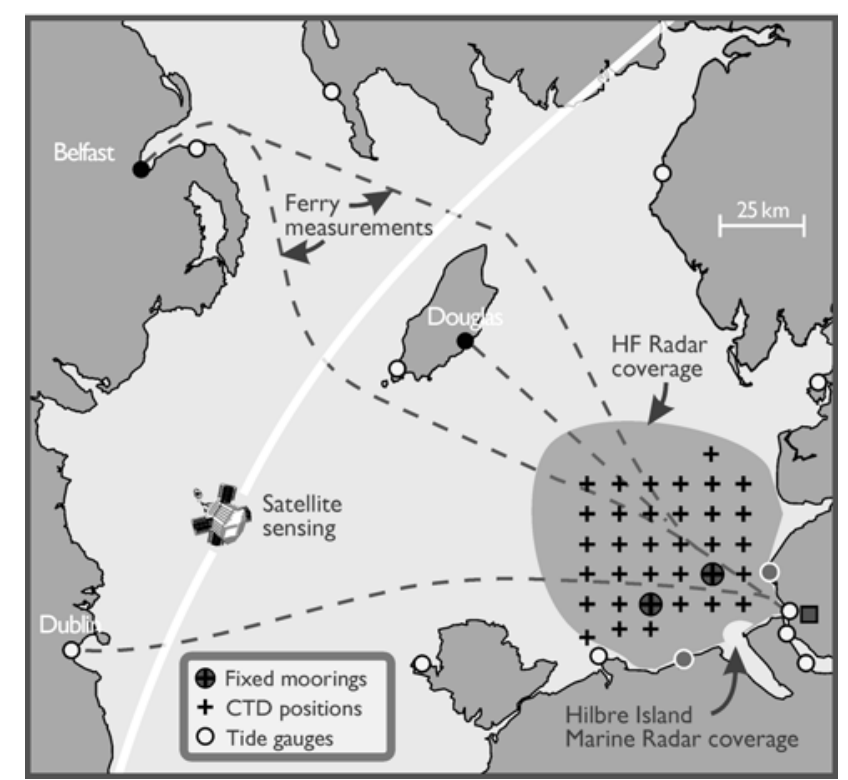

Figure 1. Liverpool Bay Coastal Observatory.

\section{HF radar}

A new method of simultaneously observing waves and currents is the WERA HF radar (Gurgel et al. 1999, Wyatt et al. 1999). This measures the directional wave spectrum as well as surface currents at a grid of points over a spatial area. The system $(12-16 \mathrm{MHz})$ operates from two shore-based sites, one near Colwyn Bay and the other near Formby Point, giving maximum coverage for resolving currents and wave conditions. The maximum range of the radar is around $100 \mathrm{~km}$ with a resolution of $2 \mathrm{~km}$ for sea surface currents and $5 \mathrm{~km}$ for 2D wave spectra. The radar was first deployed in March 2004 and real-time data are available on the Coastal Observatory website (http://cobs.pol.ac.uk). At present, only plots are available to view, updated every hour. Although there have been some teething problems we now have some confidence in the wave results since November 2005, see Fig. 2. 
Fig. 2(a) shows a scatter plot for the HF radar wave height against the WaveNet Waverider buoy (http://www.cefas.co.uk/wavenet/) which is at the same location as the Coastal Observatory primary mooring, using the nearest cell from the HF radar array for comparison. The agreement is reasonable, although further work needs to be done with quality control checks, precluding inversion of the radar Doppler spectrum for waves under certain conditions. A noticeable discrepancy is that the radar often overestimates the wave height in low sea states. It is recognized that the signal to noise ratio can be poor at low wave heights, with the threshold wave height decreasing with increasing radar frequency (Wyatt et al. 2006). Fig. 2(b) shows an instantaneous map of wave height for a time of quite strong winds. The maximum wave height observed by the radar is over $4 \mathrm{~m}$. The Waverider recorded $4.46 \mathrm{~m}$ at the same time. There is a lot of spatial variability in the radar map which may be related to the local water depth and current.

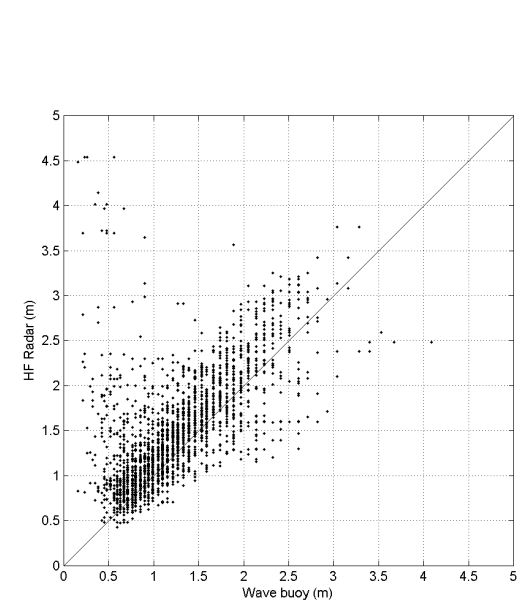

(a)

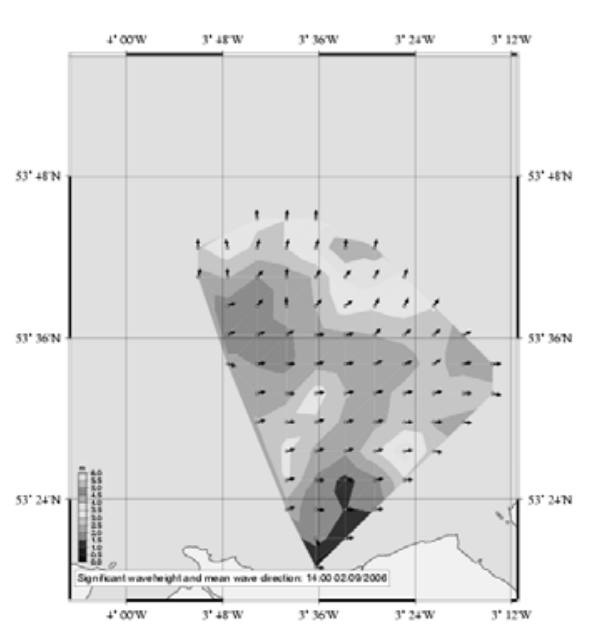

(b)

Figure 2. (a) Comparison between HF radar and buoy significant wave heights $(\mathrm{m})$ at location of Wavenet Waverider buoy (b) Map of radar wave height at 14:00 2 Sep 2006 ( wind speed at Hilbre Island $=19.46 \mathrm{~m} / \mathrm{s}$ )

Fig. 3 shows the distribution of the $\mathrm{M}_{2}$ tidal component of the surface current measured by the radar. It may be seen that there are substantial gradients of current amplitude and phase in this region with maximum $\mathrm{M}_{2}$ amplitude of over $1.2 \mathrm{~m} / \mathrm{s}$.

\section{ADCP measurements}

Another instrument which can simultaneously measure waves and the current profile is the ADCP. The Teledyne RDI ADCP Workhorse Waves Array has software which allows the current to be taken into account in the analysis of waves from the near-surface velocities. First results from this for January 2005 showed only occasionally significant differences between the analysis with and 
without currents. The high frequency measurements allow calculation of the Reynolds' stresses and hence bed stress and bottom drag coefficient, which has been done successfully for current-only (no waves) conditions (Howarth and Souza 2005). The ADCP wave height is in good agreement with the wave buoy but the periods are systematically $0.7 \mathrm{~s}$ longer. Fig. 4 shows an Hs-Tz plot for the ADCP wave data which is a useful check on data consistency. The solid line indicates the limiting steepness, $1 / 16$ in this case.
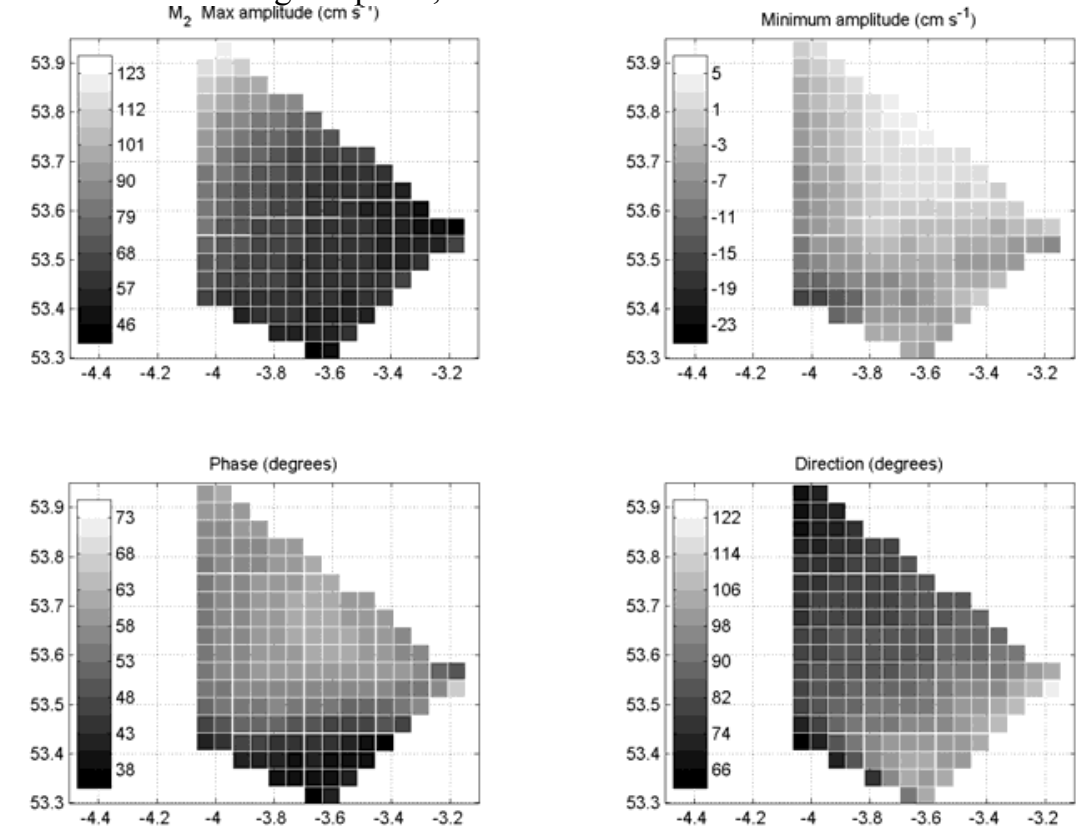

Figure 3. Results of tidal analysis of currents from HF radar. Amplitude of semi-major and semi-minor axis, phase and direction are shown for $\mathbf{M}_{2}$ tide

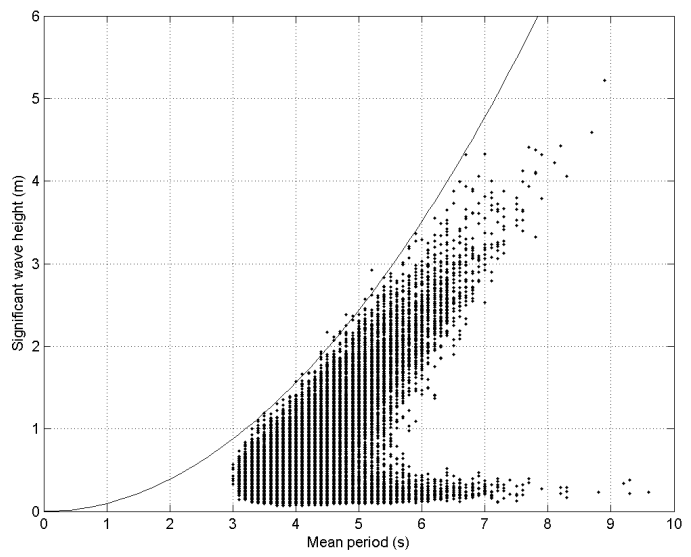

Figure 4. Hs-Tz plot for ADCP wave data December 2002 - October 2006 
Wave buoy data

A Triaxys wave buoy has been deployed almost continuously in the Hilbre Channel in the mouth of the Dee Estuary since 2004. This is a relatively sheltered location in about $10 \mathrm{~m}$ water depth (chart datum), although exposed to the NW there are drying banks (ebb and flood shoals) at the mouth of the estuary. Some results for March 2004 are shown in Fig. 5, along with wind and tide data for the same period. The maximum wave height is between 2 and $2.5 \mathrm{~m}$, and can be seen to be closely related to the local wind, which is from the $\mathrm{W}$ and NW; the wave period is mostly 3-4 seconds. The tidal modulation is in phase with the water depth where the tidal range varies from 4-8m. Purely due changes in water depth and fetch and using a constant wind of $10 \mathrm{~m} / \mathrm{s}$ the variation in wave height and period from simple fetch-limited growth laws e.g. Hurdle and Stive (1989) the change from low water to high water could be $0.3 \mathrm{~m}$ to $2.1 \mathrm{~m}$ in wave height and 1.3 to 4.3 seconds in wave period which is consistent with the order of magnitude observed. This is almost totally due to an assumed change in fetch from $2 \mathrm{~km}$ to $100 \mathrm{~km}$.
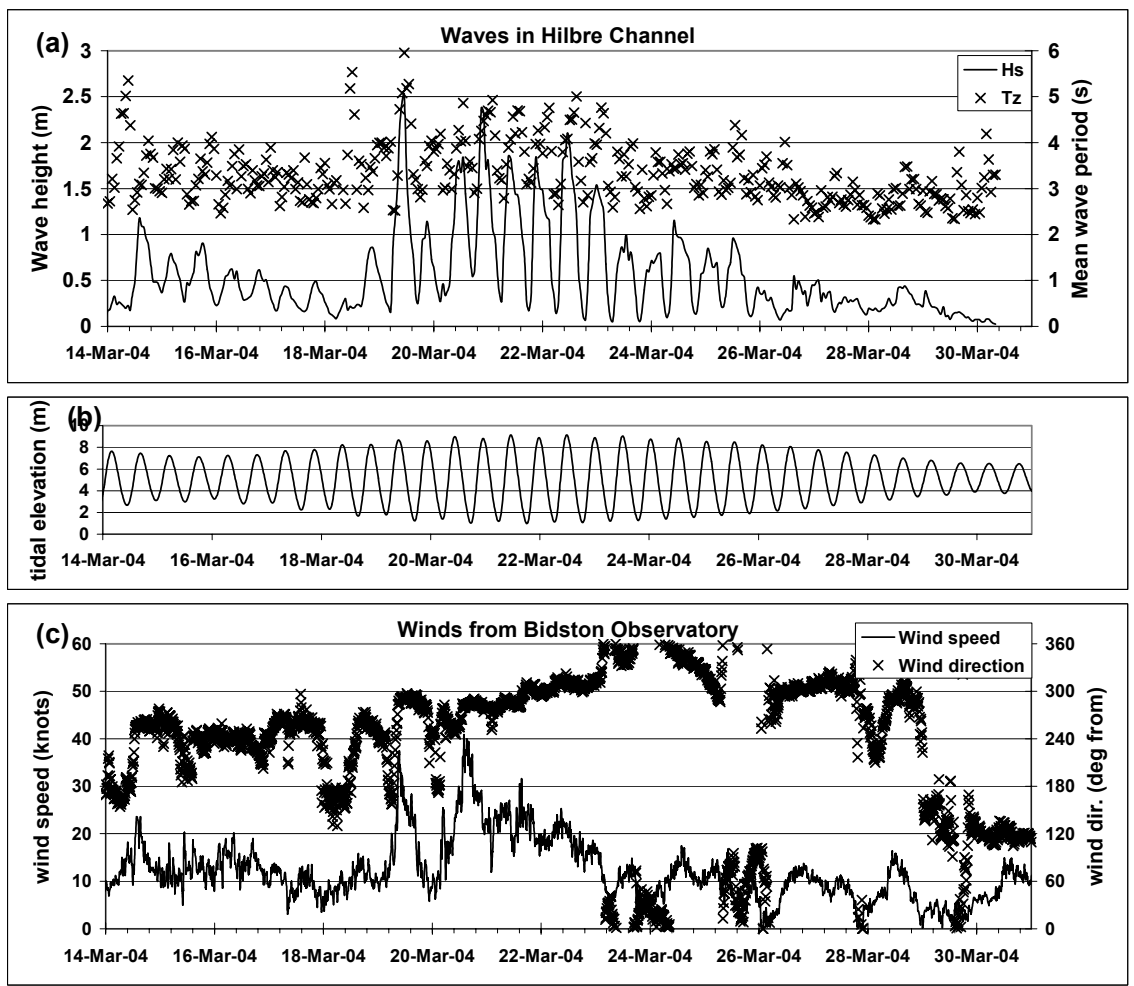

Figure 5. (a) Observations of wave height and period from Triaxys buoy in Hilbre Channel for March 2004, showing large tidal modulation (b) Tidal predictions at Hilbre for same period (c) Observations of wind speed and direction from Bidston Observatory for the same period. 


\section{DISCREPANCIES BETWEEN MODEL AND OBSERVATIONS}

Although the tidal modulation of wave height in very shallow water has been shown to be consistent with theoretical values we now examine some examples of wave-current interaction in intermediate water depths $(\sim 20 \mathrm{~m})$ and discuss the related mechanisms. Fig. 6 shows the comparison of a wave model hindcast for 26 January - 7 February 2003, using the coupled POLCOMSWAM model, forced by Met Office mesoscale model winds, with buoy and ADCP observations for the same period. The general agreement is very good but it may be seen that there are marked tidal modulations, of the wave height especially, and to a lesser extent the wave period, that are not captured by the coupled model. In fact there are only slight differences between the uncoupled (Unc) and coupled (Cou) model runs, although elsewhere in the Irish Sea it has been shown that differences reach $10 \%$ in wave height and $20 \%$ for mean period (Osuna and Wolf 2005). Although there are also some differences between the buoy and ADCP data the poorer temporal resolution of the buoy data means that it is not clear whether the oscillations are also observed by the wave buoy. The coupled model includes the combined effect of waves and currents in the bottom stress. We now discuss some of the coupling mechanisms and whether they are properly modelled. An illustration of the effects of coupling surface and bottom stress is given in Fig. 7.

For currents, the bottom stress $\left(\tau_{\mathrm{c}}\right)$ is affected by the waves through the dependency of the drag coefficient on the apparent roughness induced by the waves. The computation of bottom stress for the waves $\left(\tau_{\mathrm{w}}\right)$ is carried out using Madsen's formulation (Madsen 1994), which takes into account the current at the bottom.
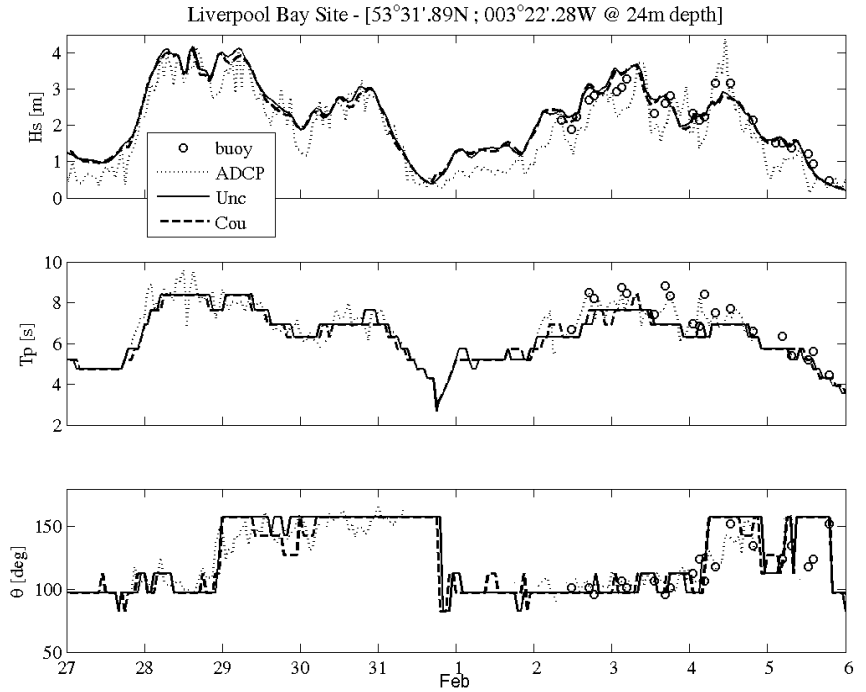

Figure 6. Comparison of model and observations at a location in Liverpool Bay 


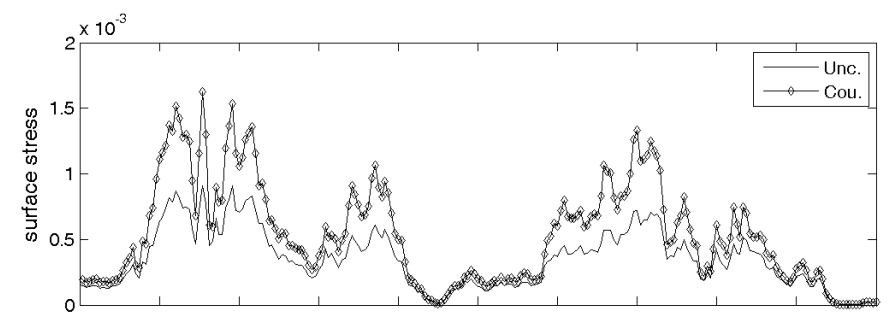

(a)

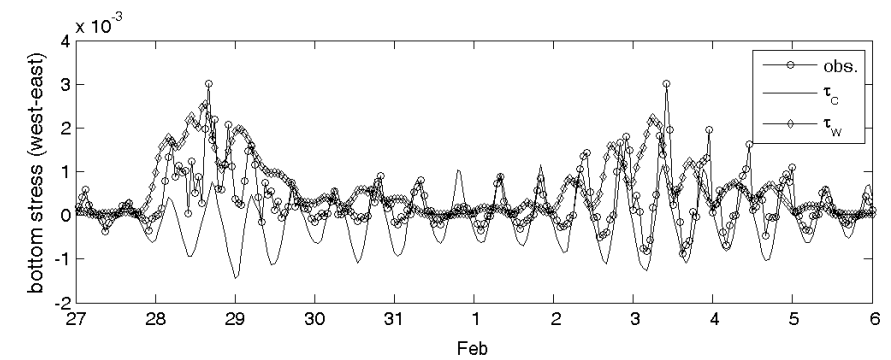

(b)

Figure 7. Comparison of (a) surface and (b) bottom stress from model and observations at a location in Liverpool Bay

\section{Surface Stress}

Substantial differences in waves and currents due to including wave effects on the surface stress have been found (Osuna and Wolf 2005), using the Janssen (1991) formulation. The effect of the relative wind is included in the coupled model. Some of these differences are related to a different way of calculating the stress, now using the Charnock relationship (Charnock 1955) as opposed to Smith and Banke (1975), hereafter referred to as SB, which was previously employed in POLCOMS, to allow the drag coefficient to be calculated from the surface roughness which comes from the wave model, as may be seen in Fig. 7 (a) in which the stress from the coupled model run (Cou) is substantially larger than that from the uncoupled (Unc) run. The Charnock coefficient, $\beta=g z_{0} / U_{*}{ }^{2}$, is related to the surface drag coefficient, $C_{D}$, the $10 \mathrm{~m}$ wind-speed, $U_{10}$ and the surface roughness length, $\mathrm{z}_{0}$, (since $U_{*}{ }^{2}=C_{D} U_{10}{ }^{2}$ ) and is often treated as a constant in models with values between 0.01 and 0.03 . If the value of $\beta$ is chosen, it can be used to derive the effective value of the roughness length from a given drag law model e.g. SB. A value of $\beta=0.0275$ is now used in the U.K. operational storm surge model (Williams and Flather 2002), having been found to give the optimum results for surges. To compare like with like the equivalent value of the Charnock parameter should be chosen (e.g. Mastenbroek et al. 1993) in our coupled model system which can then be calibrated using the database of surges from the Irish Sea. For $\beta=0.0275$ the stress ratio between the new formulation and $\mathrm{SB}$ is shown in Fig. 8. The stress is enhanced more at lower wind speeds but in general gives a higher value than SB. This explains 
part of the increase of wind-stress in Fig. 7(a) even before wave effects are included. A control run using the Charnock formulation with a constant roughness is required.

The European Centre for Medium Range Weather Forecasting coupled atmosphere-wave model allows the $10 \mathrm{~m}$ winds to be reduced in case of high drag, this feedback will ameliorate the impact of waves on the surface wind stress (Janssen 2004) and introduction of the 2-way coupled model resulted in a substantial improvement of the surface wind field forecast. It may be necessary to use a local wind model for Liverpool Bay to allow modification of the atmospheric boundary layer and also allow for local variations in wind due to the orographic effects, land-sea breezes and the coastal boundary layer.

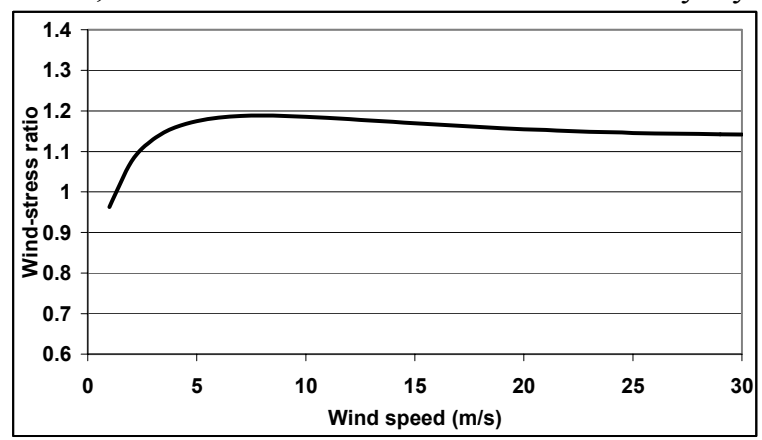

Figure 8. Wind-stress ratio for Charnock parameter $\beta=0.0275$, relative to SB

The present method of including wave-induced turbulence in the POLCOMS model, based on Craig and Banner (1994) does not carry turbulence down into the water column. The inclusion of Stokes' drift and potentially Langmuir circulation or other mechanisms in the wave model may enable better modelling of the deepening of the mixed layer without the necessity to infer large eddy viscosity which degrades the sharpness of the thermocline.

\section{Bottom Stress}

The use of ADV data for Reynolds' stress calculations is problematical for combined waves and currents. Trowbridge (1998) noted that the Reynolds' stress calculated in combined waves and currents is contaminated by waves even though the instrument should be outside the wave boundary layer although within the tidal current boundary layer and although the observations are corrected for tilt (to about $0.1 \mathrm{deg}$ ). In theory there should be no contribution from the irrotational wave motion in the covariance method of obtaining the bottom stress but in practice a very small error in tilt can produce an error contribution from the wave motion which can overwhelm the turbulent contribution. This is most likely what we see in Fig. 7(b) where the line marked 'obs' refers to the calculation of Reynolds' stress from the uncorrected turbulent velocities. 
It is not straightforward to remove the effect of waves, since waves and turbulence co-exist at wave frequencies. The method used here is to remove the part of the near-bed current fluctuations correlated with bottom pressure in the frequency band $0.05-0.5 \mathrm{~Hz}$ (Wolf 1999). Fig. 9 shows the original calculation of Reynolds' stress $\left\langle\mathrm{u}^{\prime} \mathrm{w}^{\prime}\right\rangle$ in the dominant current direction compared to that after correction for waves. The predicted quadratic bottom stress due to the mean current is also plotted and the positive part of the corrected stress is now in better agreement. This may not be the whole story however. Babanin (2006) points out that wave-induced turbulence may in fact persist throughout the water column. There has been a persistent tendency for the observed drag coefficient to be about a factor of 2 less than that typically required in numerical circulation models e.g. Howarth and Souza (2005), Wolf (1999) which suggests that the processes of near-bed turbulence and bottom stress are not fully accounted for.

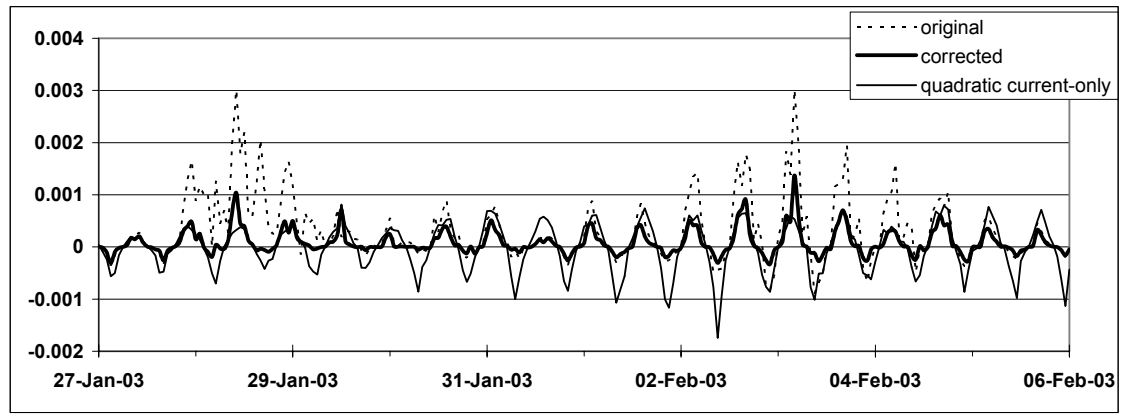

Figure 9. Calculations of bottom stress from observations in combined waves and currents

Wave-current interaction in unsteady flow

Peregrine and Jonsson (1983) and others have reviewed the mechanisms of wave-current interaction and most of these processes are taken account of in our coupled model. Radiation stresses, Stokes' drift and the effect of vertical current shear will soon be included although they are expected to be relatively small or localised. Tidal modulation of wave height and period are often observed in coastal observations e.g. Bradbury et al (2004) and see Figs. 5 and 6 above. Tolman (1991a) discussed tidal modulations of wave parameters as possible observations of wave-current interaction; however he contradicts this in his following paper (1991b) where he attributes most of the modulation to wind effects. However the wind effects discussed above do not seem sufficient to produce the observed modulation of wave height. Modulations of wave period due to Doppler shift in intermediate water depths are modelled, but the observed modulations of wave height are not reproduced. The time-variation of relative frequency is included in the wave model: it can be re-formulated purely in terms of the spatial gradient of current. The time variation of absolute frequency is not included, however:

$\omega=\sigma+\mathbf{k} . \mathbf{U}$ where $\sigma$ (intrinsic or relative wave frequency) is given by 
$\sigma=\sqrt{g k \tanh (k d)}$

$\dot{\omega}=\frac{d \omega}{d t}=\frac{\partial \sigma}{\partial d} \frac{\partial d}{\partial t}+\mathbf{k} \cdot \frac{\partial \mathbf{U}}{\partial t}$

where $\omega$ is absolute frequency, $d$ is the total water depth, $\mathbf{k}$ is the wavenumber and $\mathbf{U}$ is the current. Further work is needed to elucidate the implications of this term for the wave model.

\section{SUMMARY}

We have discussed various problems of measuring and modelling wavecurrent interaction. Are discrepancies between model and observations due to errors in the observations or some process not included in the model? What interaction terms may be missing? We are building up new datasets with simultaneous measurements of waves and currents which may be able to critically test the models. There are related problems with separation of waves, currents and turbulence form observations. Key outstanding questions are:

- Are we getting the turbulence right?

- What is the appropriate form for the wave model source terms in shallow water?

- Is Langmuir circulation important and how do we measure and model it?

- What is the effect of unsteady currents on waves?

\section{ACKNOWLEDGMENTS}

Some of the wave buoy data were obtained from the Centre for Environment Fisheries and Aquaculture Science (CEFAS) WaveNet system (http://www.cefas.co.uk/wavenet/).

\section{REFERENCES}

Ardhuin, F. and A.D. Jenkins. 2006. A practical three dimensional formalism for the ocean, coupling random waves, mean flow, and turbulence. Submitted to Journal of Fluid Mechanics.

Babanin, A.V. 2006. On a wave-induced turbulence and a wave-mixed upper ocean layer. Geophysical Research Letters, 33, L20605, doi:10.1029/2006GL027308.

Bradbury, A. P., T. E. Mason and M.W. Holt. 2004. Comparison of the performance of the Met Office UK-waters wave model with a network of shallow water moored buoy data, Proceedings of the 8th International Workshop on Wave Hindcasting and Forecasting, Hawaii, 2004.

Carniel, S., M. Sclavo, and L.H. Kantha. 2004. The influence of Langmuir cells on the velocity structure in the mixed layer, Annales Hydrographiques, 6e Ser., 3, 772, 8-1 - 8-5.

Charnock, H. 1955. Wind stress on a water surface. Quarterly Journal of the Royal Meteorological Society, 81, 639-640. 
Craig, P.D. and Banner, M.L. 1994 Modelling wave-enhanced turbulence in the ocean surface layer. Journal of Physical Oceanography, 24, 2546-2559.

Gurgel, K. -W., G. Antonischki, H. -H. Essen and T. Schlick 1999 Wellen Radar (WERA): a new ground-wave HF radar for ocean remote sensing, Coastal Engineering, 37, 219-234.

Holt, J.T. and James, I.D. 2001. An s-coordinate density evolving model of the northwest European continental shelf 1, model description and density structure. Journal of Geophysical Research, 106, C7, 14015-14034.

Howarth, M. J. and A. J. Souza. 2005. Reynolds stress observations in continental shelf seas. Deep-Sea Research II, 52(9-10): 1075-1086.

Howarth, M.J., R. Proctor, P.J. Knight, M.J. Smithson, D.K. Mills. 2006. The Liverpool Bay Coastal Observatory - towards the goals, Proceedings of Oceans'06, 18-21 September 2006, Boston, IEEE, pp6.

Hurdle, D.P and R.J.H. Stive. 1989. Revision of SPM 1984 Wave Hindcast Model to avoid inconsistencies in engineering applications, Coastal Engineering, 12, 339-351.

Janssen, P.A.E.M. 2004. The interaction of ocean waves and wind, Cambridge University Press. 300pp.

Madsen, O.S. 1994. Spectral wave-current bottom boundary layer flows, Proceedings of the $24^{\text {th }}$ ICCE. ASCE, 1:384-398.

Mastenbroek, C., G. Burgers and P.A.E.M. Janssen. 1993. The dynamical coupling of a wave model and a storm surge model through the atmospheric boundary layer. Journal of Physical Oceanography, 23, 1856-1866.

Mellor, G. 2003. The three-dimensional current and surface wave equations, Journal of Physical Oceanography, 33, 1978-1989.

Mellor, G. 2005. Some consequences of the three-dimensional current and surface wave equations, Journal of Physical Oceanography, 35, 2291-2298.

Mellor, G.L. and M.A. Donelan. 2006. A surface wave model for coupling with numerical ocean circulation models. Manuscript in preparation.

Osuna, P. and J.Wolf. 2005. A numerical study on the effect of wave-current interaction process in the hydrodynamics of the Irish Sea, Proceedings of WAVES 2005, Madrid, July, 2005.

Peregrine, D.H. and I.G. Jonsson. 1983. Interaction of waves and currents. U.S. Army Corps of Engineers Miscellaneous Reports, MR83-6. 88pp.

Rascle, N., F. Ardhuin and E.A. Terray. 2006. Drift and mixing under ocean surface: A coherent one-dimensional description with application to unstratifed conditions. Journal of Geophysical Research, 111, C03016, doi:10.1029/2005JC003004.

Smith, S.D. and E.G. Banke. 1975. Variation of the sea surface drag coe \pm cient with wind speed, Quarterly Journal of the Royal Meteorological Society, 101, 665-673.

Tolman, H. L. 1991. Effects of tides and surges on North Sea wind waves, Journal of Physical Oceanography, 21, 766-781. 
Tolman, H. L. 1991. A third-generation model for wind waves on slowly varying, unsteady and inhomogeneous depths and currents, Journal of Physical Oceanography, 21, 782-797.

Trowbridge, J. H. 1998. On a technique for measurement of turbulent shear stress in the presence of surface waves. Journal of Atmospheric and Oceanic Technology, 15, 290-298.

Williams, J. A. and R. A. Flather. 2002. Impact of new atmospheric model dynamics on operational surge model performance, Proudman Oceanographic Laboratory, Internal Document, No 145, 14 pp.

Wolf, J. 1999. The estimation of shear stresses from near-bed turbulent velocities for combined wave-current flows, Coastal Engineering, 37, 3-4, 529-543.

Wolf, J. 2004. Coupling waves and currents in POLCOMS with measurements from the coastal observatory, Annales Hydrographiques, 6th Ser., 3(772): 9-1 - 9-3.

Wyatt, L.R., S.P. Thompson and R.R. Burton 1999 Evaluation of high frequency radar wave measurement, Coastal Engineering, 37, 259-282

Wyatt, L.R., J.J. Green, A. Middleditch, M.D. Moorhead, M.J. Howarth, M. Holt, and S. Keogh. 2006. Operational wave, current and wind measurements with the Pisces HF radar, Journal of Oceanic Engineering (in press). 